\title{
Evaluation on the allocative efficiency of agricultural factors in the five Central Asian countries
}

\author{
WANG Guogang ${ }^{1}$, 'ZHANG Lin ${ }^{1}$, SUN Yuzhu², YANG Yantao ${ }^{1}$, HAN Chengji ${ }^{1}$ \\ 1. Institute of Agricultural Economics and Development, CAAS, Beijing 100081, China; \\ 2. Hebei University of Economics and Business, Shijiazhuang 050061, China
}

\begin{abstract}
Based on methods such as stochastic frontier production function, this paper analyses the changes of single factor productivity (SFP) and total factor productivity (TFP) of agriculture in the five Central Asian countries, during the period of 1992 to 2017. The research results show that the agricultural output in most of the five Central Asian countries has increased steadily, while agricultural labor productivity has shown a growth trend. With the exception of Kazakhstan, the land productivity of the other four countries shows a growth trend. In terms of factor input, the number of agricultural workers in the five Central Asian countries mainly shows a trend of decrease, with the input of chemical fertilizer increasing, and the amount of agricultural machinery increasing or decreasing within a small range. The total factor productivity in the five Central Asian countries has improved, but it is still at a low level. The policy suggestions contained in the research conclusions are as follows: (1) Promote the growth of agricultural TFP in the five Central Asian countries, and strengthen the emphasis on the input and allocation of agricultural factors; (2) be aware of the innovation of agricultural technology, as well as the promotion and diffusion of existing agricultural technologies, and improve the overall technical efficiency of agriculture; and (3) accelerate the effective flow of capital and other elements to the agricultural sector, improve infrastructure, better release the "dividend" of science and technology, and enhance the output efficiency.
\end{abstract}

Keywords: five Central Asian countries; total factor productivity; single factor productivity; allocative efficiency; technical efficiency

\section{Introduction}

Central Asia is the trade route along the world famous "Silk Road" of China, and plays an extremely important role in international agricultural cooperation. The five Central Asian countries, namely Turkmenistan, Kyrgyzstan, Uzbekistan, Tajikistan and Kazakhstan, are

Received: 2020-03-18 Accepted: 2020-07-19

Foundation: Strategic Priority Research Program of the CAS, No.XDA20040400; National Natural Science Foundation of China, No.41871184, No.41401203; The Agricultural Science and Technology Innovation Program, No.ASTIP-IAED-2020-01, No.CAAS-ZDRW202012; Central Research Institutes of Basic Research and Public Service Special Operations, No.161005202001-2

Author: Wang Guogang (1984-), PhD and Associate Professor, specialized in agricultural economics and rural development. E-mail: wangguogang@caas.cn

"Corresponding author: Zhang Lin (1981-), Professor, specialized in agricultural economics and policy.

E-mail: zhanglin02@caas.cn 
endowed with abundant agricultural resources, and this has significant mutual benefits to the agriculture of China, thus these countries are thus the main target areas for China's agriculture to "extend its reach" ( $\mathrm{Li}$ and Zhu, 2010). In recent years, China and Central Asia have been cooperating more and more extensively in such fields as agricultural trade, science and technology, and investment (Zhang, 2015). It is of great significance to comprehensively understand the agricultural development status of the five Central Asian countries, systematically evaluate their agricultural production efficiency, and explore their path and causes of agricultural growth.

Agricultural total factor productivity growth is regarded as the basis of agricultural growth, thus researchers in development economics and agricultural economics have for many years focused on agricultural TFP research. Early foreign scholars studied the growth factors of agricultural production in Japan, the United States, India and other countries. They have held that the improvement of agricultural TFP was very important in the growth of agricultural output in the United States (Grilliches, 1957; Alston, 1998; Zhang et al., 2018), and that the growth of agricultural TFP in India accounted for about one third of the output growth of this sector (Rosegrant \& Evenson, 1992). Japanese scholars have focused on the progress of agricultural technology, holding that the progress of agricultural technology was very important for Japan's agricultural economic growth. They classified the progress model of agricultural technology into the mechanistic agricultural technical progress mode, based on machinery, and the biochemical technical progress mode, based on biological capital input (Peter, 1988). Chinese scholars, e.g. Zhu (2002), began to study the progress in agricultural technology around 2000. They realized that the progress in agricultural science and technology played an important role in the growth of agricultural yield per unit area in China (Zhu, 1999; Li and Li, 2011; Wang et al., 2015). Subsequently, numerous scholars calculated the TFP and contribution rate of agricultural technology in China (Adam and Wallance, 2003; Chen, 2006; Quan, 2009; Fang, 2010).

Relevant research further explores the source of TFP growth, and decomposes agricultural TFP. It has been concluded that TFP is mainly affected by technical progress and improvement efficiency, while different countries and different agricultural industries are affected by both of them to different degrees, and the improvement efficiency is jointly determined by technical efficiency, allocative efficiency, and scale efficiency. Studies performed by Kumbhakar (2000), Vania Sena (2003), Renuka Mahadevan (2003) and others have shown that the growth of TFP results from the perspectives of frontier technical progress, relative frontier technical efficiency, relative frontier factor allocative efficiency, and relative frontier scale efficiency. According to research regarding agricultural TFP growth in China, the main source of TFP growth in China's agriculture is technical progress, while the decline of technical efficiency is the main cause hindering its growth. At present, the agricultural TFP of China increases by $5.12 \%$ annually, while the growth rate shows an overall decreasing trend. The change of scale efficiency is the main obstacle to the growth of agricultural TFP, and the change of allocative efficiency is the main factor by which to promote the growth of agricultural TFP (Zhang and Cao, 2013; Liu, 2018). In recent years, the government has paid much attention to environmental protection and ecological construction. In terms of TFP, focus has been given to the sources of inefficiency of agricultural environmental technology and green TFP (Lu, 2019; Meng, 2019). 
Generally speaking, previous studies regarding foreign agricultural TFP have mostly involved agricultural efficiency in third world countries or underdeveloped areas, and further studied the impact of technology spillover and production scale on TFP (Nadeem, 2010; Baniasadi, 2016). However, there have been few studies on agricultural TFP in Central Asian countries, especially in terms of the causes and decomposition of agricultural TFP there. In other words, the current research does not answer the question of the source of agricultural growth in Central Asian countries. In the context of implementing the Belt and Road Initiative, and based on the comprehensive measurement of the agricultural TFP in the five Central Asian countries, this study evaluates and analyses the technical efficiency and allocative efficiency of factors in efficiency improvement, and proposes corresponding countermeasures and suggestions, which provides decision support for China's agricultural enterprises to better "go global".

\section{Materials and methodology}

\subsection{Methodology and decomposition of total factor productivity}

\subsubsection{Brief introduction of the methodology}

As an important tool by which to analyze the sources of economic growth, total factor productivity (TFP) provides a vital policy basis for sustainable economic development. The efficiency research methods mainly include data envelopment analysis (DEA) and stochastic frontier analysis (SFA). Compared with the data envelopment analysis method, the stochastic frontier analysis method is more stable and less susceptible to the influence of abnormal points, and it also has a higher data fitting degree (Forsund, 1980; Gong, 1989; Coelli, 2005; Liu, 2013). Considering that the focus of this study lies in TFP, and that its decomposition levels under numerous various input factors, the C-D production function is selected as the benchmark model in this study. In addition, the stochastic frontier production function model of non-neutral technological progress considering technical inefficiency is applied for empirical analysis on the growth and composition of TFP, based on agricultural input and output of the five Central Asian countries during the period of 1992 to 2017.

The stochastic frontier production function model is generally expressed as follows:

$$
y_{i}=x_{i} \beta+\varepsilon_{i}, \varepsilon_{i}=v_{i}-u_{i}
$$

where $y_{i}$ is the actual output; $f\left(x_{i}, \beta\right)$ is the production function, presenting the best output under the existing technical conditions; $x_{i}$ is the input factor; $\beta_{j}$ is the parameter vector to be estimated; $\varepsilon_{i}$ is the mixed disturbance; $v_{i}$ is the stochastic disturbance in the conventional sense, used to distinguish measurement error and stochastic disturbance effect, normally distributed and independent of each other, $v_{i} \sim N\left(0, \sigma_{v, i}^{2}\right)$; and $u_{i}$ is the technical inefficiency of the $i$ th sample. This is the distance between the sample output and the production possibility frontier, and its existence only reduces the agricultural output. Due to its unilateral distribution, it is assumed that it obeys the semi-normal distribution, i.e., $u_{i} \sim N^{+}\left(\omega, \sigma_{u, i}^{2}\right)$.

\subsubsection{Model specification}

According to the research results of Kumbhakar (2000), VaniaSena (2003) and Renuka Ma- 
hadevan (2003), when the influence of stochastic disturbance on the frontier output is not considered, then the stochastic frontier production function model of agriculture in the five Central Asian countries can be set as follows:

$$
\ln y_{i t}=\alpha_{0}+\sum_{j} \alpha_{j} x_{j i t}+\alpha_{r} t+\left(v_{i t}-u_{i t}\right)
$$

where $y_{i t}$ is the agricultural output of the $i$ th country in the $t$ th year, expressed in terms of the agricultural GDP of the country in that year, and the time variable $t$ reflects technological changes; $x_{j i t}$ is the input of factors, wherein the input of a certain factor $j$ of the $i$ th country in the $t$ th year expressed terms of agricultural employees, forest land area, cultivated area, grassland area, dosage of chemical fertilizer and quantity of agricultural machinery; $\alpha$ and $\beta$ are the parameter vectors to be estimated; $v_{i}$ is the stochastic disturbance in the conventional sense, used to distinguish measurement error and stochastic disturbance effect, normally distributed and independent of each other, $v_{i} \sim i i d\left(0, \sigma_{v, i}^{2}\right)$; and $u_{i}$ is the technical inefficiency of the $i$ th sample. The latter is the distance between the sample output and the production possibility frontier, and its existence only reduces the agricultural output.

(1) Total factor productivity (TFP). As a representative index to evaluate production efficiency, TFP has become an important quantitative evaluation index for the economic operation quality of a production unit. TFP is the part of output growth which cannot be measured by input factors, and generally represents its change rate. The formula is as follows:

$$
T F P=\Delta y-\sum_{j=1} S_{j} \Delta x_{j}
$$

where $S_{j}$ is the share of factor $j$ in the total input factors, and $\sum_{j=1} S_{j}=1$. The contribution coefficient of factor $j$ to output growth is generally calculated by estimating the production function with econometric approach, and the estimated output elasticity coefficient is used as the approximate value of the output contribution coefficient.

(2) Technical efficiency (TE). TE refers to the ratio of the actual output of factor input to the output of frontier technology under the given frontier technology level. Assuming that the output growth rate is $\Delta y=d l n y / d t$, after decomposing the output growth rate into the contributions of frontier technology progress, the frontier technical efficiency and factor input increase to the output growth, as follows:

$$
\Delta y=\frac{d \ln f\left(x_{i t}, t\right)}{d t}-\frac{d u}{d t}=T P+\sum_{j=1} \varepsilon_{j} \Delta x_{j}-\frac{d u}{d t}
$$

The above formula shows that, under the given factor input, $d u / d t$ is positive (or negative), which signifies that the gap between the actual output and frontier output is widening (or narrowing). This reflects the deterioration (or improvement) of the technical efficiency over time. Therefore, the change of frontier technical efficiency can be expressed as $T E=-d u / d t$. TE signifies that the inefficient producers catch up with the efficient producers, or that the efficient producers pursue higher production efficiency.

(3) Allocative efficiency (AE). AE is an index by which to measure the impact of changes in input structure of factors on TFP. The formula is as follows:

$$
T F P=\Delta y-\Delta x_{j}=T P-\frac{d u}{d t}+\sum_{j=1}\left(\lambda_{j}-S_{j}\right) x_{j}+(R T S-1) \sum_{j=1} \lambda_{j} x_{j}
$$


where $\lambda_{j}\left(\lambda_{j}=\varepsilon_{j} / R T S\right)$ is the relative production elasticity of input factor $j$ in the frontier production function, and $\sum_{j=1} \lambda_{j}=1 . R T S=\sum_{j=1} \varepsilon_{j}$ is the index to measure the returns to scale. The effect of input factor on TFP growth includes the effect of the change of input structure effect of factor scale reward on the TFP growth. The impact of allocative efficiency on TFP growth can be defined as follows:

$$
A E=\sum_{j=1}\left(\lambda_{j}-S_{j}\right) \Delta x_{j}
$$

(4) Scale efficiency (SE). Economy of scale refers to the fact that the proportion of output growth is higher than that of all factors increasing in the same proportion when other conditions remain unchanged; the opposite is known as diseconomy of scale. If the total returns to scale are larger than 1, then the growth of the scale of factor input will lead to higher output growth, which is conducive to the improvement of TFP. This can be defined as follows:

$$
S E=(R T S-1) \sum_{j=1} \lambda_{j} \Delta x_{j}
$$

\subsection{Data source}

The data were mainly derived from the World Bank Database and FAO database, from during the period of 1992 to 2017. The agricultural outputs of the five Central Asian countries, i.e., Kazakhstan, Kyrgyzstan, Tajikistan, Uzbekistan and Turkmenistan, were selected. Output $y_{i t}$ is expressed in terms of the gross agricultural production of a country in that year, i.e. agricultural GDP (at constant 2010 prices, US dollars), and the data were obtained from the World Bank Database. The inputs include agricultural employees $\left(x_{1}\right)$, cultivated area $\left(x_{2}\right)$, forest land area $\left(x_{3}\right)$, grassland area $\left(x_{4}\right)$, dosage of chemical fertilizer (nitrogen, phosphate and potassium fertilizer) $\left(x_{5}\right)$ and quantity of agricultural machinery $\left(x_{6}\right)$. Among these, the data involving agricultural employees were sourced from the World Bank Database, and those regarding area, fertilizer and agricultural machinery from the FAO Database. The dosage of chemical fertilizer refers to the total dosage of the three main fertilizers, namely, nitrogen, phosphate and potassium. These variables include labor input, land input, fertilizer input, and agricultural machinery input.

\section{Analysis of single factor productivity}

\subsection{Analysis on the changes of agricultural output and factor input in the five Central Asian countries}

The agricultural added value of most of the five Central Asian countries is increasing continuously, with only Kazakhstan showing a downward trend. Compared with 1992, the changes of the agricultural GDP of Kazakhstan, Kyrgyzstan, Tajikistan, Uzbekistan and Turkmenistan in 2017 were $-5.71 \%, 75.06 \%, 144.56 \%, 856.57 \%$ and $210.61 \%$, respectively. It can be seen that the agricultural GDP in Turkmenistan has increased rapidly over the past 26 years, and has reached more than eight times that in the base period. Uzbekistan ranks second in terms of growth rate, at twice that in the base period. Since 2012, it has become the country with the highest agricultural value added among the five Central Asian countries. The agricultural GDPs of Kyrgyzstan and Tajikistan are relatively low, yet have maintained 
steady growth. For Kazakhstan, which exhibits negative growth, its agricultural added value has declined from the absolute leader among the five Central Asian countries to the second highest in 2017, with a net value of $\$ 8.8143$ billion US dollars (at constant 2010 prices). From the perspective of agricultural output, most countries have maintained a steady increase in output, and Uzbekistan shows more significant advantages in terms of agricultural output (Figure 1).

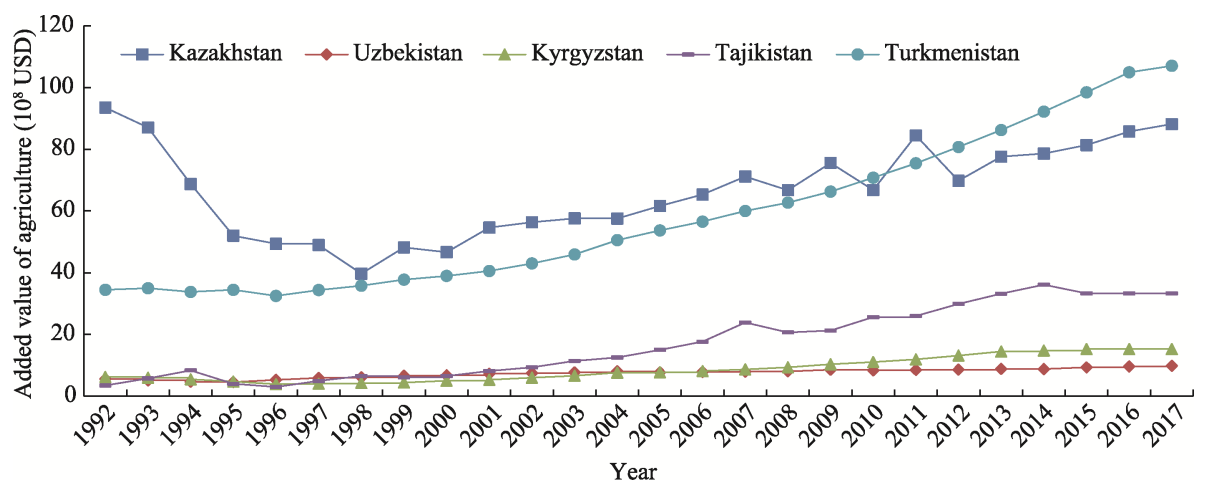

Figure 1 Changes in agricultural added value of the five Central Asian countries during 1992-2017 (at constant 2010 prices, US dollars) (0.1 billion dollars)

From the perspective of input, the agricultural land area has changed little over the past 26 years. The amount of most of the countries is trending downward, but in general does not drop significantly. In 1992, the inputs of agricultural land in Kazakhstan, Kyrgyzstan, Tajikistan, Uzbekistan and Turkmenistan were 2,214,600 mu, 100,900 mu, 44,900 mu, 353,500 $\mathrm{mu}$ and 277,200 mu, respectively; in 2017, these numbers changed to 2,169,900 mu, $105,600 \mathrm{mu}, 47,500 \mathrm{mu}, 338,400 \mathrm{mu}$ and 267,700 mu, respectively, demonstrating only a minor fluctuation. The average inputs of agricultural land in Kazakhstan, Kyrgyzstan, Tajikistan, Uzbekistan and Turkmenistan during the past 26 years were 2,156,200 mu, 106,100 $\mathrm{mu}, 46,500 \mathrm{mu}, 347,700 \mathrm{mu}$ and $270,500 \mathrm{mu}$, respectively.

Among all of the inputs, the number of agricultural employee fluctuates the most. As shown in Figure 2, most of the five Central Asian countries show a decline in this regard. In 1992, the numbers of agricultural employees in Kazakhstan, Kyrgyzstan, Tajikistan, Uzbekistan and Turkmenistan were 4,395,900, 1,056,500, 1,225,200, 343,100 and 3,961,400, respectively; while in 2017 these numbers became 2,118,600, 1,053,200, 2,822,400, 307,500 and $4,792,000$, with respective growth rates of $-51.81 \%,-0.31 \%, 130.37 \%,-10.35 \%$ and $20.97 \%$. Kazakhstan showed the sharpest decline in the number of agricultural employees, which is an important reason for the drop in its agricultural value added.

In terms of input of fertilizer and agricultural machinery, Kazakhstan's fertilizer input increased by 2.3 times from 1992 to 2017, showing an obvious growth rate, but agricultural machinery input did not change much; Kyrgyzstan's agricultural machinery input decreased significantly, and fertilizer input increased significantly; meanwhile, Uzbekistan, Turkmenistan and Tajikistan all showed a slight decrease in the use of agricultural machinery and a slight increase in the input of fertilizer (Figure 3). 


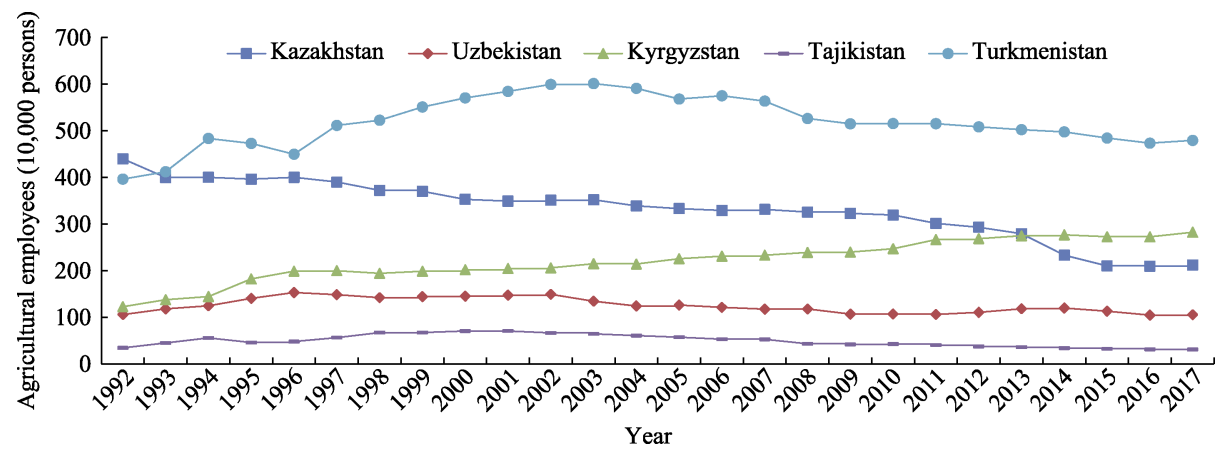

Figure 2 Number of agricultural employees in the five Central Asian countries during 1992-2017
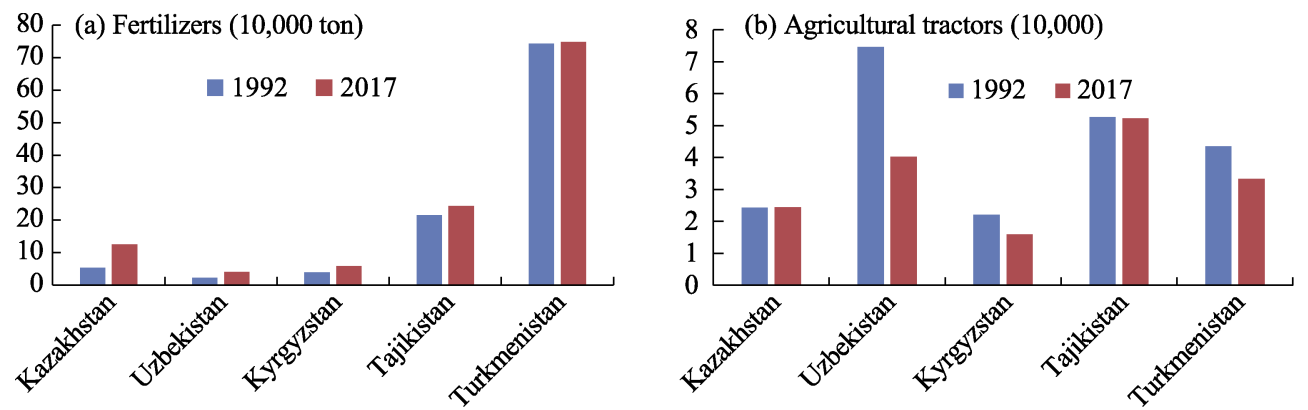

Figure 3 Agricultural input of the five Central Asian countries in 1992 and 2017

\subsection{Characteristics of changes in single factor productivity}

Land productivity, labor productivity and capital productivity are commonly collectively referred to as the "three productivities" of agricultural industry, and improving the "three productivities" is an important approach to the development of modern agriculture, as well as the main index by which to measure the level of modern agricultural development. In the following section, labor productivity and land productivity are analyzed from the perspective of data acquisition.

\subsubsection{Labor productivity}

Labor productivity is the labor efficiency of laborers in producing certain products. Agricultural labor productivity is expressed by the value of agricultural GDP created by each unit of agricultural employees, reflecting the productivity of an agricultural labor. As shown in Figure 4, the agricultural labor productivity of the five Central Asian countries showed an increasing trend from 1992 to 2017. The agricultural labor productivities of Kazakhstan, Kyrgyzstan, Tajikistan, Turkmenistan and Uzbekistan in 2017 increased by $95.64 \%, 75.61 \%$, $6.16 \%, 967.05 \%$ and $156.77 \%$, respectively, compared with those in 1992. Among the five countries, the agricultural labor productivity of Turkmenistan grew at the fastest rate, increasing by about 10 times over the 26 years. In 1992, the number of agricultural employees was 307,500 , and the agricultural added value was 348,000,000 USD; while in 2017, the corresponding numbers increased to 343,100 and 3,329,000,000 USD. The absolute superiority of 
agricultural labor productivity in Turkmenistan among the five Central Asian countries indicates that the agricultural GDP created by each unit of agricultural employees in Turkmenistan is continually increasing.

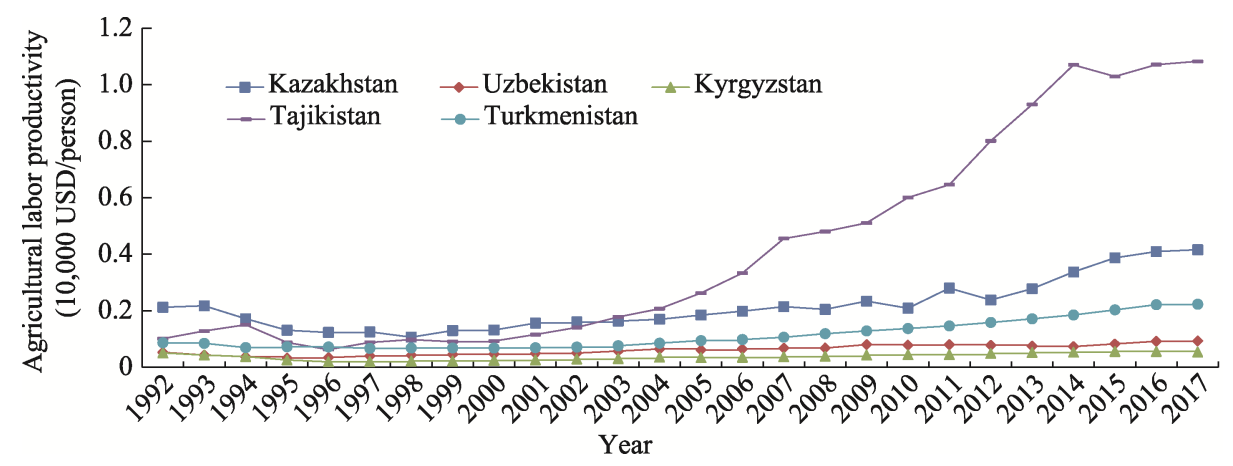

Figure 4 Changes in agricultural labor productivity of the five Central Asian countries during 1992-2017 $(\$ 10,000 /$ person $)$

\subsubsection{Land productivity}

Land productivity may be expressed by agricultural land output value per unit area. As can be seen from Figure 5, land productivity in the five Central Asian countries mainly showed an increasing trend from 1992 to 2017. Compared with 1992, in 2017 land productivity in Kazakhstan, Kyrgyzstan, Tajikistan, Turkmenistan and Uzbekistan increased by $-3.77 \%$, $67.28 \%, 131.36 \%, 899.31 \%$ and $221.67 \%$, respectively. Among these, Turkmenistan showed the fastest growth rate of land productivity, increasing by about nine times over the past 26 years. In 1992, the agricultural land area was $353,500 \mathrm{~km}^{2}$, and the agricultural added value was $\$ 348,000,000$; while the corresponding numbers in 2017 changed to $338,400 \mathrm{~km}^{2}$ and $\$ 332,900,000$. In terms of absolute value, the land productivities of Uzbekistan and Tajikistan in 2017 were $\$ 40,000 / \mathrm{km}^{2}$ and $\$ 32,200 / \mathrm{km}^{2}$, indicating that the respective values of 1 $\mathrm{km}^{2}$ reached $\$ 40,000$ and $\$ 32,200$. Except for Kazakhstan, the output value per unit area of the other four countries in Central Asia shows a trend of increase, but the rate of increase has slowed down in recent years.

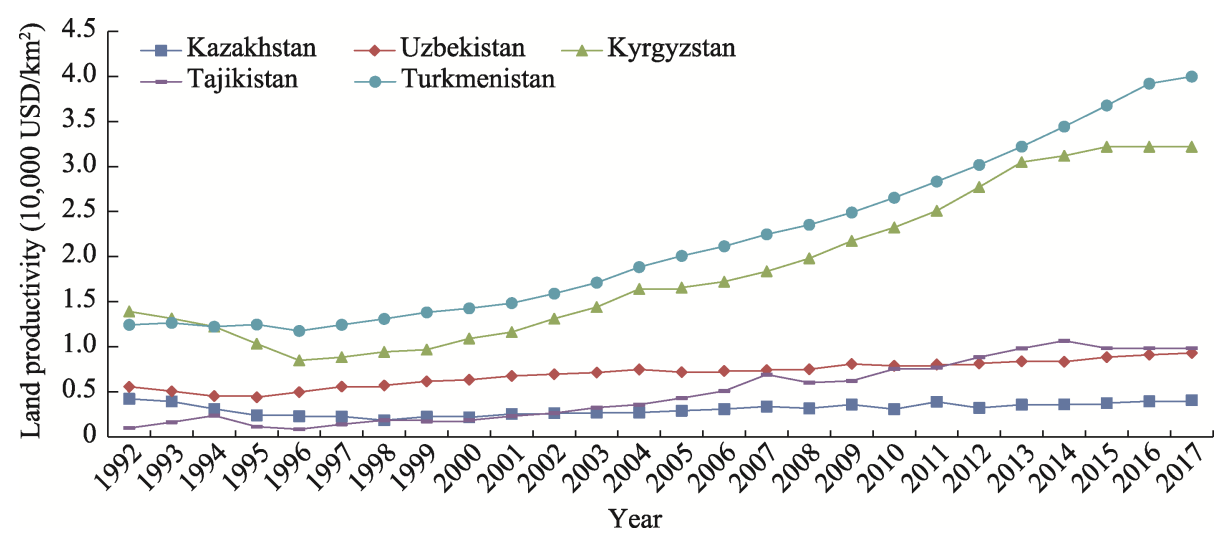

Figure 5 Changes in land productivity of the five Central Asian countries during 1992-2017 (\$10,000/km²) 


\section{Analysis on the changes of agricultural TFP in the five Central Asian countries}

\subsection{Results of model regression}

The results of model estimation are shown in Table 1. The six input variables, namely, agricultural employees $\mathrm{x} 1$, cultivated area $\mathrm{x} 2$, forest land area $\mathrm{x} 3$, grassland area $\mathrm{x} 4$, dosage of chemical fertilizer $\mathrm{x} 5$, and quantity of agricultural machinery $\mathrm{x} 6$, are all significant at the level of $1 \%$. Technical inefficiency $(u)$ has a significant impact on the agricultural output in the five Central Asian countries, $\lambda=\delta_{\mu}^{2} / \delta_{v}^{2}=0.985$. Among the technical inefficiencies, $98.50 \%$ may be artificially controlled.

Table 1 Parameter estimation results of the SFA model

\begin{tabular}{|c|c|c|c|}
\hline Item & Coefficient & Standard-error & t-ratio \\
\hline Constant term & -21.0525 & 4.0235 & -5.2324 \\
\hline Agricultural employee x 1 & 0.0377 & 0.0101 & 3.7189 \\
\hline Cultivated area $\mathrm{x} 2$ & 355.4551 & 68.3093 & 5.2036 \\
\hline Forest land area $\mathrm{x} 3$ & -6.7742 & 1.1785 & -5.7480 \\
\hline Grassland area $\mathrm{x} 4$ & 1.5575 & 0.1706 & 9.1268 \\
\hline Dosage of chemical fertilizer $\mathrm{x} 5$ & 0.7139 & 0.1425 & 5.0089 \\
\hline Quantity of agricultural machinery $\mathrm{x} 6$ & 3.8611 & 0.3486 & 11.0749 \\
\hline sigma-squared & 1250.7620 & 422.2924 & 2.9618 \\
\hline gamma & 0.9850 & 0.0049 & 200.5004 \\
\hline eta & 0.0339 & 0.0028 & 12.0895 \\
\hline log likelihood function & -392.6326 & & \\
\hline LR test of the one-sided error & 149.2228 & & \\
\hline
\end{tabular}

\subsection{Analysis of TFP in the five Central Asian countries}

As shown in Table 2, the growth of agricultural TFP in the five Central Asian countries shows a clear proceeding-phase characteristic. The agricultural TFP in Kazakhstan underwent an upward (1993-1995) - hovering (1996-2002) - upward (2003-2011) - downward (2012-2017) trend, which is fundamentally consistent with the fluctuation of the agricultural GDP. The agricultural TFP of Kazakhstan underwent great change in 2011, and the growth rate of agricultural added value also reached a high level in this year, increasing by $26.5 \%$ over the previous year. However, until 2017, the agricultural TFP continued to decline, and the TFP and agricultural added value were both the lowest in the four stages. During the past 26 years, the agricultural TFP in Kyrgyzstan and Tajikistan showed very significant cyclical fluctuation, and maintained a rising - declining - rising - declining trend. The highest value of agricultural TFP in Kyrgyzstan was 0.149 in 2009, while its lowest value was 0.014 in 2017. The highest value of agricultural TFP in Tajikistan was 0.15 in 2004, which was also the year with the highest growth rate of agricultural GDP. In 2017, the agricultural TFP in Taji- 
kistan was 0.043 , in the trough of cyclical fluctuations. The agricultural TFP of Turkmenistan dropped slowly overall, and the growth rate of its agricultural GDP also shows this trend. The agricultural TFP of Turkmenistan was 0.394 in 1993 and 0.171 in 2017. Although the TFP of Turkmenistan remained at a high level among the five Central Asian countries, its overall downward trend exhibited a negative impact on the future development of the agricultural industry. The agricultural TFP in Uzbekistan fluctuated considerably and its agricultural TFP was at a low level among the five Central Asian countries in most years. It can be seen from this that the TFP of agriculture in the five Central Asian countries is relatively low, which means that agricultural production still mainly depends on the input of capital, labor and land, while the progress of agricultural science and technology, the efficiency of factor allocation and the transformation of system and mechanism have not played a very strong role.

Table 2 Agricultural TFP of the five Central Asian countries during 1992-2017

\begin{tabular}{cccccc}
\hline Year & Kazakhstan & Kyrgyzstan & Tajikistan & Turkmenistan & Uzbekistan \\
\hline 1993 & 0.1337 & 0.0177 & 0.0703 & 0.3942 & 0.0160 \\
1995 & 0.3024 & 0.0964 & 0.1053 & 0.2219 & 0.0393 \\
2000 & 0.0637 & 0.0216 & 0.1069 & 0.0455 & 0.0015 \\
2005 & 0.0817 & 0.0263 & 0.0382 & 0.2112 & 0.0941 \\
2010 & 0.1100 & 0.0236 & 0.0377 & 0.1887 & 0.0706 \\
2015 & 0.0858 & 0.1170 & 0.0468 & 0.0919 & 0.0853 \\
2017 & 0.0213 & 0.0144 & 0.0352 & 0.0582 & 0.0434 \\
Average & 0.1144 & 0.0576 & 0.0604 & 0.1713 & 0.0598 \\
\hline
\end{tabular}

\subsection{Analysis of the efficiency improvement of the five Central Asian countries}

The TFP is mainly affected by technological progress and efficiency improvement. This paper mainly discusses the effects of technical efficiency, allocative efficiency and scale efficiency on the TFP in the five Asian countries. In general, the marginal cost and marginal benefit of production factors differ. If the cost of a production factor is relatively high, and the marginal output is relatively low compared with other factors, then the increase of input of this factor will lead to a decline in production efficiency; on the contrary, the decrease of this factor input is beneficial to the improvement of production efficiency. The modern economic growth theory suggests that the allocative efficiency of input factors depends on two aspects: one is the quantity and quality of input factors; and the other is the resource allocation mode of input factors. This means that only when the structure of input factors is fully considered can the allocative efficiency be improved by giving full play to the allocation mode of input factors. In a market economy, if factor resources can flow adequately, then the equilibrium condition for maximizing profit is that the marginal output of factor equals the cost of factor, that is to say, under this condition the contribution of allocative efficiency of factors to TFP growth should be equal to zero. According to the empirical results, the contribution of allocative efficiency of input factors to agricultural TFP growth was at a relatively low level in the five Central Asian countries from 1993 to 2017. In 1993, the agricultural allocative efficiencies of Kazakhstan, Kyrgyzstan, Tajikistan, Turkmenistan, Uzbekistan and the five countries were $-0.006,0.003,0.044,0.016,-0.008$ and -0.006 , respectively, 
and the agricultural allocative efficiencies in 2017 were $0.036,0.001,0.188,-0.005,-0.003$ and 0.036 (Table 3). Based on the theory of economic development, the equilibrium condition for maximizing profit in the market economy with sufficient flow of factor resources is that the marginal output of factors equals the cost of factors. From this perspective, the contribution of allocative efficiency (AE) of factors to TFP growth is close to zero. This shows that there is a large space for improvement in the allocation of factors in the process of agricultural production.

Table 3 Agricultural allocative efficiency (AE) of the five Central Asian countries during 1993-2017

\begin{tabular}{ccccccc}
\hline Year & Kazakhstan & Kyrgyzstan & Tajikistan & Turkmenistan & Uzbekistan & Five Central Asian countries \\
\hline 1993 & -0.0059 & 0.0031 & 0.0437 & 0.0157 & -0.0085 & -0.0059 \\
1995 & -0.0196 & -0.0011 & 0.0005 & -0.0023 & -0.0230 & -0.0196 \\
2000 & -0.0059 & 0.0031 & 0.0437 & 0.0157 & -0.0085 & -0.0059 \\
2005 & 0.0002 & -0.0003 & -0.0001 & 0.0000 & 0.0000 & 0.0002 \\
2010 & -0.0357 & -0.0011 & 0.1878 & -0.0048 & -0.0034 & -0.0357 \\
2015 & -0.0282 & 0.0061 & -0.0182 & 0.0008 & -0.0144 & -0.0282 \\
2017 & -0.0357 & -0.0011 & 0.1878 & -0.0048 & -0.0034 & -0.0357 \\
\hline
\end{tabular}

In the stochastic frontier production function, technical efficiency is a measure of the difference between the actual output and the frontier output of a certain production unit. In addition, the change rate of technical efficiency reflects the impact of the change of relative frontier technical efficiency gap on TFP. As shown in Table 1, $\eta=0.034, \eta>0$, indicating that the agricultural technical efficiency of the five Central Asian countries has gradually improved over time. That is to say, along with the sustained development of the economy, the improvement of agricultural technical efficiency has consistently increased in speed. The results show that the technical efficiency increased continuously from 1992 to 2017 (Table 4). In 1992, the agricultural technical efficiencies of Kazakhstan, Kyrgyzstan, Tajikistan, Turkmenistan and Uzbekistan were $0.30,0.49,0.47,-0.08,0.07$ and 0.25 , respectively; while these numbers in 2017 increased to $0.70,0.78,0.77,0.54,0.60$ and 0.68 , with respective growth rates of $132.61 \%, 58.90 \%, 63.93 \%, 784.09 \%, 735.45 \%$ and $169.77 \%$. Initially, the five Central Asian countries exhibited great differences in terms of agricultural technical efficiency, but with the development of technology, the difference of agricultural technical efficiency became increasingly small. Among them, Kazakhstan, Kyrgyzstan and Tajikistan showed small increases in agricultural technical efficiency, yet Turkmenistan and Uzbekistan made great improvements in agricultural technical efficiency over the 26 years.

Table 4 Agricultural technical efficiency (TE) of the five Central Asian countries during 1992-2017

\begin{tabular}{ccccccc}
\hline Year & Kazakhstan & Kyrgyzstan & Tajikistan & Turkmenistan & Uzbekistan & Five Central Asian countries \\
\hline 1992 & 0.301 & 0.492 & 0.472 & -0.079 & 0.072 & 0.252 \\
1995 & 0.369 & 0.541 & 0.523 & 0.026 & 0.162 & 0.324 \\
2000 & 0.467 & 0.613 & 0.597 & 0.177 & 0.292 & 0.429 \\
2005 & 0.550 & 0.673 & 0.660 & 0.306 & 0.403 & 0.518 \\
2010 & 0.620 & 0.724 & 0.713 & 0.414 & 0.496 & 0.593 \\
2015 & 0.679 & 0.767 & 0.758 & 0.505 & 0.574 & 0.657 \\
2017 & 0.700 & 0.782 & 0.774 & 0.537 & 0.602 & 0.679 \\
\hline
\end{tabular}


The reason for the above improvements may lie in the higher efficiency of agricultural technology extension and application. It is found that improving the efficiency of agricultural technology extension in both countries has been an effective way to improve the efficiency of agricultural technology.

\section{Conclusions and discussion}

In this paper, stochastic frontier production function and other methods are used to systematically analyze the changes of agricultural output and factor input in five Central Asian countries, measure the agricultural total factor productivity through the model, and evaluate and analyze the technical efficiency and factor allocation efficiency from the perspective of improving efficiency. We found that, during the study period, the agricultural output of most of the five Central Asian countries increased steadily, among which the agricultural labor productivity showed a growth trend; the growth of Turkmenistan reached more than nine times; in terms of land productivity, the other four countries except Kazakhstan showed an increasing trend. In terms of factor input, the number of agricultural workers in the five Central Asian countries mainly showed a trend of decrease, the input of chemical fertilizer increased, and the amount of agricultural machinery increased or decreased within a small range. From the perspective of TFP changes, the TFP values of the five Central Asian countries have increased, but they are still at a low level, which shows that their agricultural production mainly depends on the input of capital, labor and land, while the progress of agricultural science and technology, the efficiency of factor allocation and the transformation of system and mechanism have not played a very good role. In the future, attention should be paid to the promotion and application of agricultural technology, improvement of the efficiency of agricultural technology, optimization of the allocation of agricultural production factors and enhancement of the allocation efficiency, so as to jointly promote the improvement of total factor productivity.

The main policy suggestion contained in this study is that the agricultural TFP of the five Central Asian countries must be improved. This can be achieved by following these steps: First, improve the mode of factor allocation, form a more effective combination of factor allocation, enhance the efficiency of factor allocation, and in particular pay attention to increase the input of modern factors such as agricultural machinery; second, learn from China's experience and practice, accelerate the popularization, diffusion and application of agricultural technology, and improve the contribution rate of the progress in agricultural science and technology through the establishment of agricultural popularization and application demonstration system, etc.; third and finally, attach importance to agricultural investment, accelerate infrastructure construction, and more effectively release the "dividend" of science and technology, so as to improve the output efficiency.

\section{References}

Baniasadi M, 2016. Analysis the impact of technology spillovers on total factor productivity of agricultural sector in Iran. Agricultural Economics \& Development, 30(10): 117-126.

Chen W, 2006. Agricultural productivity growth, technological progress and efficiency change in China: 1990-2003. China Rural Observation, (1): 18-23, 38, 80. (in Chinese) 
Deng Z, 2010. Study on the growth and influencing factors of total factor productivity of agriculture in China [D]. Chongqing: Southwest University. (in Chinese)

Fang F, Zhang Y, 2010. Analysis on the change of China's agricultural TFP and its influencing factors based on Malmquist index method from 1991 to 2008. Economic Theory and Economic Management, (9): 5-12. (in Chinese)

Førsund F R, Lovell C A K, Schmidt P, 1980. A survey of frontier production functions and of their relationship to efficiency measurement. Journal of Econometrics, 13(13): 5-25

Fried L, Schmidt Y, 2002. Accounting for environmental effects and statistical noise in data envelopment analysis. Journal of Productivity Analysis, (17): 121-136.

Li Y, Li T, 2011. Empirical analysis of international competitiveness of agriculture in Xinjiang and Central Asia. Agricultural Technology Economy, (10): 121-128. (in Chinese)

Li Y, Zhu X, 2010. Prospect analysis of agricultural cooperation between China and five Central Asian countries under the background of agricultural "Going Out”. Issues in Agricultural Economy, 31(9): 42-48. (in Chinese)

Liu Z, 2018. Dynamic evolution of China's agricultural total factor productivity and analysis of its influencing factors. China's Agricultural Resources and Regionalization, 39(12): 104-111. (in Chinese)

Lu N, Zhu L, 2019. Study on technological efficiency of agricultural environment and growth of green total factor productivity in China. Agricultural Technological Economy, (4): 95-103. (in Chinese)

Meng X, Zhou H, Du L et al., 2019. Change of technical efficiency of agricultural environment and growth of green total factor productivity in China: A re-examination based on the perspective of combination of cultivation and cultivation. Issues in Agricultural Economy, (6): 9-22. (in Chinese)

Nadeem N, Javed M S, Hassan S et al., 2010. Decadewise analysis of total factor productivity growth of agriculture sector in Punjab, Pakistan: 1970-2005. Journal of Agricultural Research, 48(1): 93-104.

Nigel Key, 2019. Farm size and productivity growth in the United States Corn Belt. Food Policy, 84: 186-195.

Peter M, 1988. The intercountry agricultural production function and productivity differences among countries. Journal of Development Economics, 28(1): 121-124.

Quan J, 2009. Empirical analysis of China's agricultural total factor productivity growth: 1978-2007: Based on stochastic frontier analysis (SFA). Rural Economy of China, (9): 36-47. (in Chinese)

Rada N E, Fuglie K O, 2019. New perspectives on farm size and productivity. Food Policy, 84: 147-152.

Ruttan V W, 2002. Productivity growth in world agriculture: Sources and constraints. American Economic Association, 16(4): 161-184.

Van den Broeck J, Koop G, Osiewalski J et al., 1994. Stochastic frontier models: A Bayesian perspective. Journal of Econometrics, 61(2): 273-303.

Wang G G, Liu Y S, Li Y R et al., 2015. Dynamic trends and driving forces of land use intensification of cultivated land in China. Journal of Geographical Sciences, 25(1): 45-57.

$\mathrm{Wu}$ J, 1996. A brief discussion on the choice of agricultural technology progress model. Issues in Agricultural Economy, (8): 40-43. (in Chinese)

Yang Y, Li X, Dong W et al., 2019. Assessing China's human-environment relationship. Journal of Geographical Sciences, 29(8): 1261-1283.

Zhang J Y, Chen Y N, Li Z, 2018. Assessment of efficiency and potentiality of agricultural resources in Central Asia. Journal of Geographical Sciences, 28(9): 1329-1340.

Zhang L, Cao J, 2013. China's agricultural total factor productivity growth: Introduction of allocation efficiency change: An empirical analysis based on stochastic frontier production function method. China's Rural Economy, (3): 4-15. (in Chinese)

Zhang Y, Yang G, Yang Y, 2015. The strategy of "one belt and one road": Strengthening the opportunity of agricultural cooperation between China and Central Asia. International Economic Cooperation, (1): 31-34.

Zhu X, 2002. Estimation of contribution rate of agricultural science and technology progress in the Ninth Five-Year Plan period. Issues in Agricultural Economy, (5): 12-13. (in Chinese)

Zhu X, 1999. Analysis of China's grain productivity growth. Issues in Agricultural Economy, (7): 2-9. (in Chinese) 